\title{
Methods to identify the target population: implications for prescribing quality indicators
}

\author{
Liana Martirosyan*1, Onyebuchi A Arah², Flora M Haaijer-Ruskamp', Jozé Braspenning³ and Petra Denig1
}

\begin{abstract}
Background: Information on prescribing quality is increasingly used by policy makers, insurance companies and health care providers. For reliable assessment of prescribing quality it is important to correctly identify the patients eligible for recommended treatment. Often either diagnostic codes or clinical measurements are used to identify such patients. We compared these two approaches regarding the outcome of the prescribing quality assessment and their ability to identify treated and undertreated patients.
\end{abstract}

Methods: The approaches were compared using electronic health records for 3214 diabetes patients from 70 general practitioners. We selected three existing prescribing quality indicators (PQI) assessing different aspects of treatment in patients with hypertension or who were overweight. We compared population level prescribing quality scores and proportions of identified patients using definitions of hypertension or being overweight based on diagnostic codes, clinical measurements or both.

Results: The prescribing quality score for prescribing any antihypertensive treatment was $93 \%$ (95\% confidence interval 90-95\%) using the diagnostic code-based approach, and $81 \%$ (78-83\%) using the measurement-based approach. Patients receiving antihypertensive treatment had a better registration of their diagnosis compared to hypertensive patients in whom such treatment was not initiated. Scores on the other two PQI were similar for the different approaches, ranging from 64 to $66 \%$. For all PQI, the clinical measurement -based approach identified higher proportions of both well treated and undertreated patients compared to the diagnostic code -based approach.

Conclusions: The use of clinical measurements is recommended when PQI are used to identify undertreated patients. Using diagnostic codes or clinical measurement values has little impact on the outcomes of proportion-based PQI when both numerator and denominator are equally affected. In situations when a diagnosis is better registered for treated than untreated patients, as we observed for hypertension, the diagnostic code-based approach results in overestimation of provided treatment.

\section{Background}

In the last decade, many prescribing quality indicators (PQI) have been developed to measure whether the right drugs are prescribed to the right patients [1]. They are being used for quality improvement initiatives, and to identify and reward providers who meet predefined standards of quality. For assessing prescribing quality, it is important to correctly identify the target population, i.e. patients with a specific condition who should receive a specific treatment. The validity of such identification

\footnotetext{
* Correspondence: Imartirossyan@yahoo.com

1 Department of Clinical Pharmacology, University Medical Center Groningen, University of Groningen, Groningen, the Netherlands

Full list of author information is available at the end of the article
}

depends not only on source of data but also on the type of information used to define a condition [2].

It has been recognized that the data source used can influence the outcome of the quality assessment. Administrative data, which are created mainly for billing purposes, often do not provide sufficient detail for reliable quality assessment [3-5]. Medical records provide a good alternative since they contain more detailed information although it can be difficult to extract all relevant information from this data source [6]. Aside from the data source, the operational definition of a condition may influence the outcome of the quality assessment. To identify the target population, i.e. patients in need of a specific treatment, either diagnostic codes or clinical measurements indicative of a disease or condition can be used. For 
example, to assess the quality of treatment in patients with hypertension, one can calculate the percentage of patients with the diagnosis of hypertension prescribed the recommended treatment [7-10], or the percentage of patients with elevated blood pressure levels being prescribed the recommended treatment [11-14].

These different approaches to define the target population give rise to several possible problems. Using information from recorded diagnoses can introduce bias due to incomplete registration when some patients with a condition do not have a corresponding diagnostic code registered in the data or due to incorrectly registered diagnostic codes[15,16]. Missing eligible patients is especially problematic for internal quality assessment, when health care providers use PQI as screening tools to identify patients who may benefit from the improved treatment. Using clinical measurements, on the other hand, may lead to missing patients with well-controlled disease states. In both cases, incorrect estimates of prescribing quality can occur when the accuracy of identification is not equal for treated and untreated patients. If this bias varies between providers, it can introduce misclassification on provider level and mislead pay-for-performance programs when better score on quality indicators is linked to financial incentives.

Little is known about the impact of the chosen approach to define the target population on the assessment of prescribing quality. The objective of our study was to compare the approach based on diagnostic codes registered in electronic health records (EHR) to the approach based on clinical measurements registered in EHR addressing the following questions:

1. Does the chosen approach affect prescribing quality scores?

2. What is the ability of the two approaches to identify well treated and undertreated patients?

For this study, existing PQI were selected focusing on glucose lowering and antihypertensive treatment in patients with type 2 diabetes mellitus. This is a field where both internal and external quality assessment are becoming priority for health care systems, and knowledge about the impact of the chosen approach to define the target population is important for accurate and meaningful quality measurement.

\section{Methods}

\section{Study setting and sample}

In The Netherlands, patients are registered with a single general practitioner (GP) who has a gatekeeper role in coordinating their medical care. Almost all GPs used electronic health records. For our study, we used data from all T2DM patients registered with 70 GPs working in 37 practices in the North of the Netherlands. These GPs participate in the GIANTT project that collects rou- tinely documented data, such as demographics, prescribed medication, diagnoses and clinical measurements, from the EHR of the patients. An approval to use the data for this study was obtained from the Steering Committee of the GIANTT project was obtained on April 7, 2006.

Patients with T2DM were identified through screening of the electronic medical records of the GPs using text terms for diabetes (including diab*, dm, type 2, type II), diagnostic codes for diabetes (ICPC-code T90.x) [17], record flags for diabetes, and diabetes medication (ATCcode A10) [18]. All identified patients were classified by a research assistant and verified by their GP as having type 2 diabetes mellitus using the WHO classification of diabetes [19]. In general, T2DM patients visit their GP every three months, and routine blood pressure measurements are usually conducted during these visits.

\section{Data collection}

An automatic data extraction method was used which was described previously, and is very sensitive (97-100\%) in detecting relevant clinical measurement information, e.g. blood pressure and body mass index (BMI) values, irrespective of registration method or information system used by the GP [20]. The method relies on text recognition to ensure retrieval of information from 'free text' segments of the records in addition to data collection from structured tables, comparable to a manual chart review. Diagnoses are collected from the problem lists in the EHR where the GPs document medical problems pertaining to the patient using either the International Classification for Primary Care (ICPC) [17] coding or text lines, which were manually recoded into the corresponding ICPC codes by two researchers verified by an experienced GP. All participating GPs prescribed electronically, which means that the dataset included full information regarding prescribed medication.

\section{Prescribing quality indicators (PQI)}

We included PQI that have been developed for assessing prescribing quality in T2DM patients. These PQI were derived from evidence-based diabetes guidelines, and previously tested in expert panels $[9,10,21,22]$. For this study, we selected two PQI focusing on the treatment of patients with hypertension and one PQI focusing on glucose management in obese or overweight patients. Both hypertension and overweight can be defined using diagnostic codes or clinical measurement values, and the required information is commonly available in the EHR (table 1). These three PQI represent different aspects of prescribing in different subgroups of T2DM patients. For the first indicator (PQI-1), the clinical measurement is directly influenced by the recommended treatment which may result in missing patients with a well-controlled dis- 
Table 1: Definitions of the PQI according to the diagnostic code-based approach, the clinical measurement-based approach, and the reference method

\begin{tabular}{|c|c|c|c|}
\hline & Diagnostic code-based & Clinical measurement-based & Reference (hybrid) method \\
\hline \multirow[t]{2}{*}{ PQI-1 } & $\begin{array}{l}\text { Denominator: T2DM patients with } \\
\text { diagnostic codes for hypertension }\end{array}$ & $\begin{array}{l}\text { Denominator: T2DM patients with } \\
S B P \geq 140 \mathrm{mmHg}\end{array}$ & $\begin{array}{l}\text { Denominator: T2DM patients with } \\
\text { diagnostic codes for of hypertension OR } \\
S B P \geq 140 \mathrm{mmHg}\end{array}$ \\
\hline & $\begin{array}{l}\text { Numerator: Denominator AND } \\
\text { prescription of any antihypertensive } \\
\text { medication }\end{array}$ & $\begin{array}{l}\text { Numerator: Denominator AND } \\
\text { prescription of any antihypertensive } \\
\text { medication }\end{array}$ & $\begin{array}{l}\text { Numerator: Denominator AND } \\
\text { prescription of any antihypertensive } \\
\text { medication }\end{array}$ \\
\hline \multirow[t]{2}{*}{ PQI-2 } & $\begin{array}{l}\text { Denominator: T2DM patients with } \\
\text { diagnostic codes for hypertension } \\
\text { and history of IHD or MI }\end{array}$ & $\begin{array}{l}\text { Denominator: T2DM patients with } \\
\mathrm{SBP} \geq 140 \mathrm{mmHg} \text { AND history of IHD } \\
\text { or } \mathrm{MI}\end{array}$ & $\begin{array}{l}\text { Denominator: T2DM patients with } \\
\text { diagnostic codes for hypertension OR } \\
\mathrm{SBP} \geq 140 \mathrm{mmHg} \text { AND history of IHD or MI }\end{array}$ \\
\hline & $\begin{array}{l}\text { Numerator: denominator AND } \\
\text { prescription of beta blocker }\end{array}$ & $\begin{array}{l}\text { Numerator: Denominator AND } \\
\text { prescription of beta blocker }\end{array}$ & $\begin{array}{l}\text { Numerator: Denominator AND } \\
\text { prescription of beta blocker }\end{array}$ \\
\hline \multirow[t]{2}{*}{ PQI-3 } & $\begin{array}{l}\text { Denominator: T2DM patients with } \\
\text { diagnostic codes for overweight OR } \\
\text { obesity }\end{array}$ & $\begin{array}{l}\text { Denominator: T2DM patients with } \\
\mathrm{BMI} \geq 25\end{array}$ & $\begin{array}{l}\text { Denominator: T2DM patients with } \\
\text { diagnostic codes for overweight OR } \\
\text { obesity OR BMI } \geq 25\end{array}$ \\
\hline & $\begin{array}{l}\text { Numerator: Denominator AND } \\
\text { prescription of metformin }\end{array}$ & $\begin{array}{l}\text { Numerator: denominator AND } \\
\text { prescription of metformin }\end{array}$ & $\begin{array}{l}\text { Numerator: denominator AND } \\
\text { prescription of metformin }\end{array}$ \\
\hline
\end{tabular}

T2DM: Type 2 Diabetes Mellitus, IHD: Ischaemic Heart Disease, MI: myocardial infarction, SBP: Systolic Blood Pressure, BMI: Body Mass Index (weight in kilograms divided by height in meters-squared)

ease state when using clinical measurements. This is partly the case for PQI-2, although the recommended $\beta$ blocker may not be the main treatment prescribed for lowering the blood pressure. For PQI-3, there is no direct effect of the recommended treatment on the control of the condition.

\section{Data analysis}

All the analyses were conducted using data from the EHR. The PQI were calculated using prescribing information from the second half of 2004. All preceding diagnosis information regarding hypertension (ICPC-codes K85, K86 and K87) and overweight or obesity (ICPCcodes T82 and T83) was used for the diagnostic codebased approach. For the clinical measurement-based approach, an average systolic blood pressure (SBP) of $\geq 140 \mathrm{mmHg}$ during the first half of 2004 was used to define hypertensive patients, and the most recent BMI value in 2004 being $\geq 25$ was used to define overweight patients. We used an average SBP $\geq 140 \mathrm{mmHg}$ as a cut off value to identify patients with hypertension following the recommendations for treatment of T2DM patients with hypertension described in the Dutch Hypertension Guidelines for General Practitioners [23].

To check whether the inclusion of patients with an 'average' of only one elevated SBP value in the study period might be unjustified, we assessed how many of such patients had no preceding or next SBP values $\geq 140$ $\mathrm{mm} / \mathrm{Hg}$. This was the case for only $2 \%$ of the patients with elevated average SBP levels in the first half of 2004.

To select T2DM patients with history of ischemic heart disease or myocardial infarction (PQI-2) we have used ICPC codes K74, K76, and K75. All analyses were conducted using SPSS version 16.0 (SPSS, Inc., Chicago, Illinois).

To answer our first question, we calculated the PQI scores with $95 \%$ confidence intervals using only diagnostic codes or only clinical measurement values. The unit of analysis for calculation of the PQI scores was an individual patient, therefore the prescribing quality scores discussed in this paper are population level scores. We used mixed model analysis to adjust the scores of PQI and their 95\% confidence intervals for correlation within GP practices. For our second question, we calculated the ability of each approach to identify 'well treated' patients (patients receiving the treatment as recommended), and 'undertreated' patients (patients in need of treatment but not receiving the recommended treatment). This was expressed as the proportion of 'well treated' (respectively 'undertreated') patients identified with either approach from the total number of 'well treated' (respectively 'undertreated') patients identified with the reference method, where we combined diagnostic codes with clinical measurement values (box1).

Finally, we repeated the analyses in a subset of patients that had at least one registered blood pressure or BMI 
value during the study period to assess the impact of incomplete registration of clinical measurements on the comparison of the two approaches.

\section{Results}

The dataset included 3214 T2DM primary care patients with an average age of 67 years and diabetes duration of 6 years; $55 \%$ were women (Table 2). Of the patients, 32\% had a registered diagnosis of hypertension, and $7 \%$ had a diagnosis of overweight. Blood pressure measurements were available for $80 \%$ of the patients, and BMI measurements for $66 \%$ of patients. Among patients with registered measurements, $55 \%$ had an average systolic blood pressure $\geq 140 \mathrm{mmHg}$, and $55 \%$ had a BMI $\geq 25$.

Concurrence between registration of diagnostic codes and the corresponding clinical measurements was low. Among patients with an elevated systolic blood pressure, $62 \%$ (1086) did not have a registered diagnostic code for hypertension. In case of overweight, 92\% (1624) of patients with $\mathrm{BMI} \geq 25$ did not have a registration of a corresponding diagnostic code (table 3 ).

\section{Scores of PQI}

The choice of approach affected the outcome of only PQI-1 focusing in prescription of any antihypertensive treatment. For this PQI the diagnostic code-based approach resulted in $12 \%$ higher prescribing quality score than measurement-based approach. For the remaining two indicators, the prescribing scores observed with different approaches were nearly identical (table 4).

\section{Ability of identifying well treated and undertreated patients}

The use of either diagnostic codes or clinical measurements to identify well treated or undertreated patients resulted in absolute differences in proportions of identified patients ranging from $15 \%$ to $84 \%$ (table 5). In all cases, the measurement-based approach identified more well treated and undertreated patients than the diagnostic code-based approach. For well treated patients, the proportion identified raised from $54 \%$ (diagnostic codebased) to $84 \%$ (measurement-based) for antihypertensive treatment in general (PQI-1), from $63 \%$ to $79 \%$ for beta blocker treatment after ischemic heart diseases (PQI-2), and from $12 \%$ to $97 \%$ for metformin treatment in overweight patients (PQI-3). Similarly, the proportion of undertreated patients identified increased from 21\% (diagnostic code-based) to $88 \%$ (measurement-based) for PQI-1, from $60 \%$ to $75 \%$ for PQI-2, and from $11 \%$ to $95 \%$ for PQI-3 when clinical measurements were used (table $5)$.

Using the diagnostic code-based approach, a clear difference was observed in its ability to identify well treated versus undertreated patients for antihypertensive treatment in general (PQI-1). This approach identified 54\% of
Table 2: Characteristics of the study population $(\mathrm{N}=3214)$

\begin{tabular}{ll}
\hline Characteristic & Value \\
\hline Age, mean in years (SD) & $67.1(12.6)$ \\
\hline Women, $\mathrm{n}(\%)$ & $1767(55.0)$ \\
\hline Duration of diabetes, mean in years (SD) & $6.0(5.6)$ \\
\hline & \\
\hline Registered diagnosis of hypertension, $\mathrm{n}(\%)$ & $984(31.0)$ \\
\hline $\begin{array}{l}\text { Registered diagnosis of overweight or } \\
\text { obesity, } \mathrm{n}(\%)\end{array}$ & $213(6.6)$ \\
\hline Registered diagnosis of IHD or MI, $\mathrm{n}(\%)$ & $367(11)$ \\
\hline Registered systolic blood pressure, $\mathrm{n}(\%)$ & $2566(79.8)$ \\
\hline Registered Body Mass Index, $\mathrm{n}(\%)$ & $2106(65.5)$ \\
\hline \begin{tabular}{l} 
Systolic blood pressure $\geq 140$ mmHg, $\mathrm{n}(\%)$ \\
\hline
\end{tabular} \\
\hline
\end{tabular}

the well treated but only $21 \%$ of the undertreated patients, indicating that the registration of a hypertension diagnosis in the EHR is more likely when drug treatment is initiated than when drug treatment is not (yet) initiated. Such bias was not observed for the other two PQI (table 5).

\section{Subset analysis}

We repeated the analyses in subsets of patients that had at least one recorded blood pressure measurement for PQI-1 (1939 of the 2070 hypertensive patients) and PQI-2 (227 of the 251 hypertensive patients with IHD or MI), and at least one BMI value for PQI-3 (1772 of the 1837 overweight patients). The PQI scores for the subset were quite similar to scores observed for the whole study population. According to the reference method, the prescribing quality scores calculated for the subsets changed from $81 \%$ to $82 \%$ for PQI-1, from $63 \%$ to $64 \%$ for PQI-2, and remained $65 \%$ for PQI-3. For the diagnostic code-based approach, observed changes were $92 \%$ to $94 \%$ (PQI-1), $65 \%$ to $66 \%$ (PQI-2), $65 \%$ to $70 \%$ (PQI-3). As could be expected, the proportion of identified well treated and 
Table 3: Eligibility agreement between registration of diagnoses and clinical measurements

\begin{tabular}{lccc}
\hline & $\begin{array}{c}\text { Diagnosis } \\
\text { Yes }\end{array}$ & Diagnosis & No \\
& 663 & 1086 & 1749 \\
\hline SBP $\geq 140$ & 190 & 627 & 817 \\
\hline SBP $<140$ & 131 & 517 & 648 \\
\hline No SPB & 984 & 2230 & 3214 \\
\hline Total & 143 & 1624 & 1767 \\
\hline BMI $\geq 25$ & 5 & 334 & 339 \\
\hline BMI $<25$ & 65 & 1043 & 1108
\end{tabular}

SBP: Systolic Blood Pressure

BMI: Body Mass Index (weight in kilograms divided by height in meters-squared)

undertreated patients with the measurement-based approach increased for this subset of patients, and approached the reference method with proportions of $89 \%, 86 \%, 100 \%$ for well treated and $95 \%, 85 \%, 100 \%$ for undertreated patients.

\section{Discussion}

Our study showed that prescribing quality scores do not necessarily change when using different approaches to define the number of patients eligible for treatment. However, when diagnosis is registered better for treated than for untreated patients, as was the case for hyperten- sion, the diagnostic code-based approach resulted in overestimating the prescribing quality (93 versus $81 \%$ ). In addition, it became clear that incomplete registration of diagnostic codes is a big problem for conditions such as hypertension and overweight, leading to the identification of low proportions of patients in need of treatment (11-60\%) when using a diagnostic code-based approach.

In general, PQI are proportion-based measures which can be quite robust to changes in the numerator, as any change in the numerator causes changes in the denominator [24]. This was the case for the indicators focusing on the prescription of beta blockers and of metformin in

Table 4: Scores of prescribing quality indicators identified with different approaches

\begin{tabular}{|c|c|c|}
\hline \multirow[t]{2}{*}{ Prescribing quality indicators (PQI) } & \multicolumn{2}{|c|}{$\begin{array}{l}\text { Outcome of the PQI, \%, }(95 \% \mathrm{Cl}) \text { numerator/ } \\
\text { denominator }\end{array}$} \\
\hline & Diagnostic code-based & Measurement-based \\
\hline PQI-1 Prescription of any antihypertensive medication in hypertensive & $93(90-95)$ & $81(78-83)$ \\
\hline T2DM patients & $1412 / 1749$ & $905 / 984$ \\
\hline PQI-2 Prescription of beta blocker in hypertensive T2DM patients with a & $65(57-72)$ & $64(56-72)$ \\
\hline history of IHD or MI & $100 / 155$ & $125 / 194$ \\
\hline \multirow[t]{2}{*}{ PQI-3 Prescription of metformin in overweight T2DM patients } & $65(59-72)$ & $66(62-69)$ \\
\hline & $39 / 213$ & $1154 / 1767$ \\
\hline
\end{tabular}

T2DM: Type 2 Diabetes mellitus

IHD: Ischaemic Heart Disease

MI: Myocardial Infarction 
Table 5: Identification of well treated and undertreated patients using the diagnostic code-based and clinical measurement-based approach

\begin{tabular}{|c|c|c|c|c|c|}
\hline \multirow[b]{2}{*}{ Type of approach } & \multicolumn{2}{|c|}{ Well treated patients } & \multicolumn{2}{|c|}{ Undertreated patients } & \multirow[b]{2}{*}{$\begin{array}{c}\mathrm{N} \text { of eligible } \\
\text { patients per PQI }\end{array}$} \\
\hline & $\begin{array}{l}\text { proportion } \\
\text { detected*, \% }\end{array}$ & $\mathbf{N}$ & $\begin{array}{l}\text { Proportion } \\
\text { detected }^{* *}, \%\end{array}$ & $\mathbf{N}$ & \\
\hline \multicolumn{5}{|c|}{ PQI-1 Prescription of any antihypertensive medication in hypertensive T2DM patients } & 2070 \\
\hline Reference method & - & 1687 & - & 383 & \\
\hline Diagnostic code-based, hypertension & $54(905 / 1687)$ & 905 & $21(79 / 383)$ & 79 & \\
\hline Measurement-based, SBP $\geq 140$ & $84(1412 / 1687)$ & 1412 & $88(337 / 383)$ & 337 & \\
\hline \multicolumn{5}{|c|}{ PQI-2 Prescription of beta blocker in hypertensive T2DM patients with a history of IHD or MI } & 251 \\
\hline Reference method & - & 159 & - & 92 & \\
\hline Diagnostic code-based, hypertension & $63(100 / 159)$ & 100 & $60(55 / 92)$ & 55 & \\
\hline Measurement-based, SBP $\geq 140$ & $79(125 / 159)$ & 125 & $75(69 / 92)$ & 69 & \\
\hline \multicolumn{5}{|c|}{ PQI-3 Prescription of metformin in overweight T2DM patients } & 1837 \\
\hline Reference & - & 1193 & - & 644 & \\
\hline Diagnostic code-based, overweight or obesity & $12(139 / 1193)$ & 139 & $11(74 / 644)$ & 74 & \\
\hline Measurement-based, BMI $\geq 25$ & $97(1154 / 1193)$ & 1154 & $95(613 / 644)$ & 613 & \\
\hline $\begin{array}{l}\text { T2DM: Type } 2 \text { Diabetes mellitus } \\
\text { SBP: Systolic Blood Pressure } \\
\text { BMI: Body Mass Index (weight in kilograms divi } \\
{ }^{*} \text { Number of treated patients detected through } \\
\text { method } \\
\text { **Number of untreated patients detected thro } \\
\text { reference method }\end{array}$ & $\begin{array}{l}\text { by height in met } \\
\text { tested approach } \\
\text { the tested appro }\end{array}$ & $\begin{array}{l}\text { ared) } \\
\text { by the } \\
\text { ded by }\end{array}$ & $\begin{array}{l}\text { hber of treated pa } \\
\text { number of untrea }\end{array}$ & $\begin{array}{l}\text { s acco } \\
\text { atien }\end{array}$ & $\begin{array}{l}\text { to the reference } \\
\text { ording to the }\end{array}$ \\
\hline
\end{tabular}

specific patient groups (PQI-2 and PQI-3). However, for the indicator focusing on the prescription of any antihypertensive drug (PQI-1), the diagnostic code-based approach resulted in a higher score on prescribing quality compared to the clinical measurements-based and reference methods. The explanation of this finding is that the registration of the diagnostic codes for hypertension is more likely once antihypertensive treatment is prescribed, as was illustrated by the low percentage of untreated in comparison to treated hypertensive patients identified with the diagnostic code-based approach. A similar finding was observed in non-diabetic population, where treated patients also had a better registration of the diagnosis of hypertension [25].

In our study population, the clinical measurementbased approach identified higher proportion of patients who are in need of treatment compared to the diagnostic code-based approach. This is due to the fact that many patients with either high blood pressure or BMI levels did not have a registration of the corresponding diagnostic code in the EHR. Poor registration of conditions such as hypertension and especially overweight in the EHR seems to be a common problem [26-28]. It has therefore been advocated to use clinical measurements to improve documentation of such conditions [29]. Improved registration of diagnostic codes as a part of quality improvement programs may make diagnostic code-based PQI more reliable. It is important to realize, however, that the validity of registered diagnoses is influenced by many factors including the purpose of registration, skills and knowledge of the coder, insensitive coding schemes for registering specific diseases, prioritizing the coding of some conditions over others by physicians, and completeness of a disease classification system $[15,30]$.

Clinical measurement values appear to be a better choice for prescribing quality assessment, especially for internal quality assurance, when it is crucial to correctly identify as many patients who could benefit from the improved treatment. When the clinical measurement values are influenced by the recommended treatment, as is 
the case for PQI-1 and PQI-2, a clinical measurementbased approach for assessing the treatment may result in missing patients with well-controlled disease states. This is particularly a problem when patient eligibility and prescribed treatment are assessed cross-sectionally [14]. When prescribing is assessed in a sequential way (i.e. after the observed clinical measurement), as was done in our study, missing well-controlled patients appeared not to affect the quality scores. In situations where there are already much higher percentages of well-controlled patients, however, a measurement-based approach can result in lower prescribing quality scores in comparison to a diagnostic code-based approach.

In our study we used cut off levels of SBP $\geq 140 \mathrm{mmHg}$ to identify patients with hypertension as advised by Dutch hypertension guidelines. However, World Health Organization (WHO) and International Society of Hypertension (ISH) advised to use lower cut off levels of SBP to diagnose hypertension in T2DM patients [31]. Use of lower values of SBP to identify hypertensive patients may result in larger differences between the PQI scores when the different approaches are used.

We used a sensitive method for data abstraction from medical records. Registration of diagnostic codes was complemented by recoding diagnoses from text lines. Our reference method was based on a combination of available information about diagnosis and measurements documented in the EHR. Although EHR are often considered the gold standard for quality measurement, inadequate registration of both diagnoses and clinical measurements affects this reference method. Our subset analysis, however, showed that the prescribing quality scores were not affected by incomplete registration of clinical measurements. The PQI scores and proportions of identified patients may not be generalizable to other databases with different registration rates of clinical measurements or diagnostic codes but the identified problems are likely to occur in other settings. The registration rates in our dataset were similar to those described in other studies conducted in different parts of the world using EHR of both diabetic and general primary care population [25,32,33].

Finally, it has to be kept in mind that if these PQI are used for comparison of individual GPs, the number of eligible patients per PQI per GP may not be sufficient for reliable benchmarking. To address the problem of a small sample size per PQI, one could choose from several existing methods including pooling data from several health care providers or time periods or excluding indicators or health care providers with small patient numbers [21].

Although in our study setting the ICPC codes were used, we expect that the results of our study are also relevant for health care systems using the International Classification of Diseases (ICD), as this classification system also includes diagnostic codes for hypertension, overweight and obesity that could be combined or substituted with clinical measurement values.

\section{Conclusion}

To our knowledge, this is the first study addressing the impact of using different types of information to define a condition on the assessment of prescribing quality. With the increasing use of electronic health records, which offer more complete information than administrative data, EHR have the potential to provide sensitive estimates of healthcare quality. Our study shows some drawbacks of using either diagnostic codes or clinical measurement values from the EHR for prescribing quality assessment. Although both approaches resulted in missing patients who could benefit from the recommended treatment, the use of clinical measurements is more sensitive to screen for poorly treated patients. This is important for quality improvement purposes. When there is information bias in the documentation of diagnoses in relation to the treatment status, the use of diagnostic codes alone can mislead both policy makers and health care providers about the performance scores of quality indicators. In such cases, a combination of diagnostic codes and clinical measurement information is recommended for prescribing quality assessment.

\section{Competing interests}

The authors declare that they have no competing interests.

\section{Authors' contributions}

LM originated the idea for this study, did the research proposal, data analysis, and prepared the manuscript. PD and HR-FM contributed to the research proposal, reviewed the analysis, and participated in the preparation of the manuscript. JB participated in the interpretation of the data and in the discussion of the paper. OAA participated in the data analyses and edited and reviewed the manuscript. All authors read and approved the final manuscript.

\section{Acknowledgements}

The authors of the study would like to thank the Groningen Initiative to Analyse Type 2 Diabetes Treatment (GIANTT) group. The GIANTT group are D. de Zeeuw, F.M. Haaijer-Ruskamp, P. Denig (Department of Clinical Pharmacology, University Medical Centre Groningen), B.H.R. Wolffenbuttel (Department of Endocrinology, University Medical Centre Groningen), K. van der Meer (Department of General Practice, University Medical Centre Groningen), K. Hoogenberg (Department of Internal Medicine, Martini Hospital Groningen), P. Bijster (Regional Diabetes Facility, General Practice Laboratory LabNoord, Groningen), P. Rademaker (District Association of General Practitioners, Groningen), R.P. Stolk (Department of Clinical Epidemiology, University Medical Centre Groningen), H.J.G. Bilo (Isala Clinics, Zwolle; Department of Internal Medicine, University Medical Centre Groningen).

\section{Author Details}

1Department of Clinical Pharmacology, University Medical Center Groningen, University of Groningen, Groningen, the Netherlands, ${ }^{2}$ Department of Epidemiology, University of California, Los Angeles (UCLA), School of Public Health, Los Angeles, California, USA and ${ }^{3}$ Scientific Institute for quality of Healthcare, Radboud University Nijmegen Medical Centre, Nijmegen, the Netherlands

Received: 2 October 2009 Accepted: 26 May 2010 Published: 26 May 2010 


\section{References}

1. Hoven JL, Haaijer-Ruskamp FM, Stichele RH Vander: Indicators of prescribing quality in drug utilisation research: report of a European meeting (DURQUIM, 13-15 May 2004). Eur J Clin Pharmacol 2005, 60:831-834

2. Gulliford MC, Charlton J, Latinovic R: Predictive validity of different definitions of hypertension for type 2 diabetes. Diabetes Metab Res Rev 2006, 22:361-366.

3. Peabody JW, Luck J, Jain S, Bertenthal D, Glassman P: Assessing the accuracy of administrative data in health information systems. Med Care 2004, 42:1066-1072.

4. Keating NL, Landrum MB, Landon BE, Ayanian JZ, Borbas C, Guadagnoli E: Measuring the quality of diabetes care using administrative data: is there bias? Health Serv Res 2003, 38:1529-1545.

5. Pawlson $L G$, Scholle SH, Powers A: Comparison of administrative-only versus administrative plus chart review data for reporting HEDIS hybrid measures. Am J Manag Care 2007, 13:553-558.

6. Persell SD, Wright JM, Thompson JA, Kmetik KS, Baker DW: Assessing the validity of national quality measures for coronary artery disease using an electronic health record. Arch Intern Med 2006, 166:2272-2277.

7. Asch SM, Kerr EA, Keesey J, Adams JL, Setodji CM, Malik S, McGlynn EA: Who is at greatest risk for receiving poor-quality health care? NEng/J Med 2006, 354:1147-1156.

8. Garjon Parra FJ, Aller Blanco Al, Buisan Giral MJ, Elfau Mairal M, Celaya Lecea MC: Selection of quality indicators for primary care prescription through a consensus group. Aten Prim 2006, 38:39-44.

9. Majumdar SR, Johnson JA, Bowker SL, Booth GL, Dolovich L, Ghali W, Harris SB, Hux JE, Holbrook A, Lee HN, Toth EL, Yale GF: A Canadian consensus for the standardized evaluation of quality improvement interventions in type 2 diabetes. Canadian Journal of Diabetes 2005, 29:220-229

10. Min LC, Mehrotra R, Fung CH: Quality indicators for the care of hypertension in vulnerable elders. J Am Geriatr Soc 2007, 55:359-365.

11. Asch SM, Kerr EA, Lapuerta P, Law A, McGlynn EA: A New Approach for Measuring Quality of Care for Women With Hypertension. Arch Intern Med 2001, 161:1329-1335.

12. Campbell SM, Roland MO, Shekelle PG, Cantrill JA, Buetow SA, Cragg DK: Development of review criteria for assessing the quality of management of stable angina, adult asthma, and non-insulin dependent diabetes mellitus in general practice. Qual Health Care 1999, 8:6-15.

13. Rodondi N, Peng T, Karter AJ, Bauer DC, Vittinghoff E, Tang S, Pettitt D, Kerr EA, Selby JV: Therapy modifications in response to poorly controlled hypertension, dyslipidemia, and diabetes mellitus. Ann Intern Med 2006, 144:475-484.

14. Voorham J, Denig P, Wolffenbuttel BH, Haaijer-Ruskamp FM: Crosssectional versus sequential quality indicators of risk factor management in patients with type 2 diabetes. Med Care 2008, 46:133-141.

15. Botsis T, Bassoe CF, Hartvigsen G: Sixteen years of ICPC use in Norwegian primary care: looking through the facts. BMC Medical Informatics and Decision Making 2010, 10:11.

16. Solberg LI, Engebretson Kl, Sperl-Hillen JM, O'Connor PJ, Hroscikoski MC, Crain AL: Ambulatory care quality measures for the 6 aims from administrative data. Am J Med Qual 2006, 21:310-316.

17. Lamberts $\mathrm{H}$, Wood M: The birth of the International Classification of Primary Care (ICPC) Serendipity at the border of Lac Leman. Fam Pract 2002, 19:433-435.

18. World Health Organization: ATC index. WHO Collaborating Centre for Drug Statistics Methodology [http://www.whocc.no/atc ddd index/. Accessed on April 12, 2010

19. World Health Organization: Definition, diagnosis and classification of diabetes mellitus and its complicatons: Report of a WHO Consultation. Geneva: World Health Organization, Department of Noncommunicable Disease Surveillance; 1999

20. Voorham J, Denig P: Computerized Extraction of Information on the Quality of Diabetes Care from Free Text in Electronic Patient Records of General Practitioners. J Am Med Inform Assoc 2007, 14:349-354.

21. Martirosyan L, Braspenning J, Denig P, de Grauw WJ, Bouma M, Storms F, Haaijer-Ruskamp FM: Prescribing quality indicators of type 2 diabetes mellitus ambulatory care. Qual Saf Health Care 2008, 17:318-323.
22. Steel N, Melzer D, Shekelle PG, Wenger NS, Forsyth D, McWilliams BC: Developing quality indicators for older adults: transfer from the USA to the UK is feasible. Qual Saf Health Care 2004, 13:260-264.

23. Wiersma Tj, Walma EP, Thomas S: Derde herziening van de NHGStandaard Hypertensie. Hart bulletin 2004, 35:9-20.

24. Stuart B, Singhal PK, Magder LS, Zuckerman IH: How robust are health plan quality indicators to data loss? A Monte Carlo simulation study of pediatric asthma treatment. Health Serv Res 2003, 38:1547-1561.

25. Asch SM, McGlynn EA, Hiatt L, Adams J, Hicks J, DeCristofaro A, Chen R, LaPuerta P, Kerr EA: Quality of care for hypertension in the United States. BMC Cardiovasc Disord 2005, 5:1.

26. Bardia A, Holtan SG, Slezak JM, Thompson WG: Diagnosis of Obesity by Primary Care Physicians and Impact on Obesity Management. Mayo Clinic Proceedings 2007, 82:927-932.

27. Woolthuis EPK, de Grauw WJ, van Gerwen WH, Hoogen HJ van den, Lisdonk EH van de, Metsemakers JF, van Weel C: Identifying people at risk for undiagnosed type 2 diabetes using the GP's electronic medical record. Family Practice 2007, 24:230-6.

28. Vellinga A, O'Donovan D, De La Harpe D: Length of stay and associated costs of obesity related hospital admissions in Ireland. BMC Health Services Research 2008, 8:88.

29. Bordowitz R, Morland K, Reich D: The use of an electronic medical record to improve documentation and treatment of obesity. Fam Med 2007, 39:274-279.

30. Starfield B: Primary Care: Balancing Health Needs, Services, and Technology. New York: Oxford University Press; 1998

31. Whitworth JA: 2003 World Health Organization (WHO)/International Society of Hypertension (ISH) statement on management of hypertension. J Hypertens 2003, 21:1983-1992.

32. Lusignan S, Sismanidis C, Carey IM, DeWilde S, Richards N, Cook DG: Trends in the prevalence and management of diagnosed type 2 diabetes 1994-2001 in England and Wales. BMC Fam Pract 2005, 6:13.

33. Rafter N, Wells S, Stewart A, Selak V, Whittaker R, Bramley D, Roseman P, Furness $S$, Jackson RT: Gaps in primary care documentation of cardiovascular risk factors. NZMed J 2008, 121:24-33.

Pre-publication history

The pre-publication history for this paper can be accessed here: http://www.biomedcentral.com/1472-6963/10/137/prepub

doi: 10.1186/1472-6963-10-137

Cite this article as: Martirosyan et al., Methods to identify the target population: implications for prescribing quality indicators BMC Health Services Research 2010, 10:137

\section{Submit your next manuscript to BioMed Central and take full advantage of:}

- Convenient online submission

- Thorough peer review

- No space constraints or color figure charges

- Immediate publication on acceptance

- Inclusion in PubMed, CAS, Scopus and Google Scholar

- Research which is freely available for redistribution
C) BioMed Central 